\title{
Transgresión y persistencia: la represión de las manifestaciones musicales profanas en los espacios religiosos de la periferia chilena. Siglos XVI-XIX*
}

\section{TRANSGRESSION AND PERSISTENCE: THE REPRESSION OF SECULAR MUSICAL FORMS IN RELIGIOUS SPACES FROM THE CHILEAN PERIPHERY. 16TH - 19TH CENTURIES}

TRANSGRESSÃO E PERSISTÊNCIA: A REPRESSÃO DAS FORMAS MUSICAIS SECULARES EM ESPAÇOS RELIGIOSOS PERIFERIA CHILENO. SIGLOS XVI-XIX

\section{José Miguel Ramos Fuentes **}

\section{Gonzalo Martínez García ***}

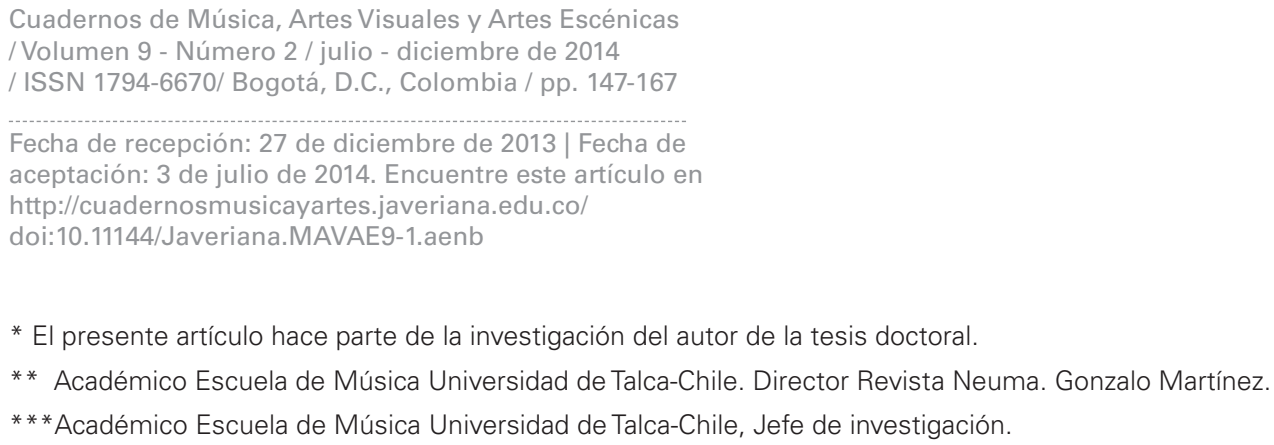

Cuadernos de Música, Artes Visuales y Artes Escénicas / Volumen 9 - Número 2 / julio - diciembre de 2014

/ ISSN 1794-6670/ Bogotá, D.C., Colombia / pp. 147-167

Fecha de recepción: 27 de diciembre de 2013 | Fecha de aceptación: 3 de julio de 2014. Encuentre este artículo en http://cuadernosmusicayartes.javeriana.edu.co/ doi:10.11144/Javeriana.MAVAE9-1.aenb

* El presente artículo hace parte de la investigación del autor de la tesis doctoral.

* Académico Escuela de Música Universidad de Talca-Chile. Director Revista Neuma. Gonzalo Martínez.

***Académico Escuela de Música Universidad de Talca-Chile, Jefe de investigación. 


\section{Resumen}

El presente artículo aborda, desde el concepto de centro y periferia, las dinámicas producidas en torno a la actividad musical religiosa periférica en Chile durante los siglos XVI al XIX. Específicamente, en cuanto a las particularidades generadas, primero, por las continuas normativas dictadas desde la Iglesia católica, dirigidas a frenar ciertos aspectos considerados como indebidos y alejados de la sobriedad que quiso imponérsele a la liturgia, y, segundo, en cuanto a la permanente y persistente presencia de elementos seculares en esta, que, vistos desde el concepto expuesto al inicio, se manifiesta como una dinámica de espacios y actores sociales diversos, en una sociedad marcada por la desigual pirámide social.

Palabras clave: Iglesia católica; manifestaciones profanas; persistencia; represión; centro-periferia; Chile

\section{Abstract}

This article discusses, from the concept of center and periphery, the dynamics produced around peripheral religious musical activity in Chile during the sixteenth to the nineteenth centuries. Specifically in regard to the specific generated first by the ongoing regulations issued from the Catholic Church, aimed at curbing certain aspects considered improper and away from the sobriety that would be imposed on the liturgy, and second, in terms of permanent and persistent presence of secular elements in it, which, seen from the concept put at the beginning, manifests as a dynamic spaces and various social actors in a society marked by the unequal social pyramid.

Keywords: Catholic Church; secular manifestations; persistence; repression; centerperiphery; Chile

\section{Resumo}

Este trabalho aborda, desde o conceito do centro e periferia, as dinâmicas produzidas em torno à atividade musical religiosa periférica no Chile durante os séculos XVI ao XIX. Especificamente em quanto às particularidades geradas, primeiro, pelas continuas normativas ditadas desde a Igreja Católica, dirigidas a frear certos aspectos considerados como indevidos e afastados da sobriedade que quis se impor à liturgia, e segundo, em quanto a permanente e persistente presença de elementos seculares na mesma, que olhados desde o conceito exposto no começo, se manifesta como uma dinâmica de espaços e atores sociais diversos, numa sociedade marcada pela pirâmide de desigualdade social.

Palavras-chaves: Iglesia católica; manifestações profanas; persistencia; repressão; centro-periferia; Chile 
La actividad musical vinculada a la liturgia católica en América comenzó junto con la llegada del peninsular a comienzos del siglo XVI, y, si bien el nivel de desarrollo que tuvo dicha actividad en Chile no fue equivalente al alcanzado en los principales polos virreinales, aproximarnos a conocer su devenir histórico nos parece del mayor interés.

Numerosos documentos permiten vislumbrar la fuerte presencia de manifestaciones musicales seculares en el ámbito religioso, a través de la constante, aunque fallida, intención de reprimirlos por parte de las autoridades eclesiásticas. Como han demostrado estudios anteriores, y nuestra investigación también lo atestigua, las prácticas musicales en Chile durante el período mencionado fueron mucho más allá del ámbito de la Catedral de Santiago y la capital del Reino.

Uno de los principales estudios al respecto es el trabajo de Maximiliano Salinas (2000) que aborda las dinámicas de la represión desde el prisma de la imposición de un canon monocultural occidental en América, canon que tiene como centro la dogmática católica. El autor enfatiza que la imposición de dicho canon fue producto de las dinámicas de poder de una elite política y religiosa, entre los siglos XVI y XVII, y una elite ilustrada a partir del siglo XVIII. Lejos de rechazar la visión del autor, nuestro estudio se basa en una hipótesis que amplía dicha visión: proponemos que no es posible entender la actitud de la Iglesia al implantar dicho canon solamente desde la perspectiva de la mantención del poder de las elites por dos razones: primero, sostenemos que lo que se rechaza en primera instancia es la conjunción de ciertas prácticas culturales y espacios religiosos, ya sean estos lugares $u$ ocacionalidades, consagrados a la gravedad de la doctrina'; y segundo, sostenemos además que en el siglo XIX no solo se rechazan prácticas culturales de los grupos subalternos, sino también prácticas propias de la elite que surgieron como efecto de la modernidad.

Nuestro trabajo se basa en una metodología de carácter mixto, como la propuesta por Leonard Meyer (2000, pp. 30-32, 69-107), quien considera necesario situar el fenómeno musical dentro de una serie de constricciones de carácter histórico, social y cultural, permitiendo obtener una mirada integral del objeto de estudio. Dicha metodología consiste en tres fases: primero, constatar hechos, luego generar una hipótesis explicativa sobre dichos hechos y, finalmente, comprobar dicha hipótesis. Por una parte, el levantamiento de información que nos dé cuenta de este fenómeno, a través de la revisión de documentos de archivo (ordenanzas, sínodos, pastorales y decretos) y la literatura que aborda solo de manera tangencial el tema. Sin embargo, lo que nos ha permitido elaborar la hipótesis mencionada ha sido la conjunción de la metodología expuesta con la utilización de una herramienta conceptual, ampliamente usada en las ciencias sociales, que ha constreñido nuestra investigación. Dicha herramienta es el concepto de centro y periferia.

El concepto de centro utilizado como metáfora de lo propio, lo cercano, tiene una larga data en la historia de la humanidad, teniendo una de sus primeras manifestaciones plásticas en el símbolo del mandala, símbolo ubicuo tanto temporal como geográficamente. En este sentido, la idea de centro implica una concepción que mide la distancia, puesto que establece 
límites: al entender lo que representa el centro, entendemos también que hay algo que no pertenece a él, algo que está lejos, fuera, incluso. Es así que la idea de centro implica la de periferia, independiente del término que usemos para representarla: si se delimita el campo de lo propio, inmediatamente se delimita lo ajeno, creando entonces un límite que permite concebir un "adentro" y un "afuera". Además de las manifestaciones plásticas, la idea de centro permea también desde antiguo el concepto de lo urbano, al constreñir la concepción urbanística de las antiguas ciudades españolas, por ejemplo. Estas eran construidas alrededor de un centro, en el que se encontraba la plaza pública, la catedral y el cabildo, todos ellos elementos simbólicos del orden establecido tanto temporal como sagrado. Y a medida que crecían hacia "afuera", se establecía claramente una relación simbólica entre la lejanía, "la periferia", "el afuera" y el centro.

Tal vez por eso, por su carga simbólica, y porque efectivamente -al constituir una metáfora fundamental en la psicología occidental- ha constreñido la representación de las relaciones sociales, influyendo en la vida diaria de las personas a lo largo de la historia, es que la musicología tradicional chilena se ha visto influida por este concepto como herramienta epistemológica.

El concepto de centro y periferia ha permeado así la musicología en Chile de dos formas no excluyentes: por un lado, afirmando que Chile representaba la periferia respecto del centro, la capital del Virreinato, lo que implicaba y explicaba (recursivamente) la condición de ruralidad o frontera del reino; y, por otro, sugiriendo que, dado el gran estado de aislamiento y pobreza existente en el periodo colonial, toda actividad musical relevante se generó en Santiago, la capital del Reino, y, especialmente, en su Catedral. Hasta inicios de la década de los noventa la mayoría de los estudios musicológicos sobre la colonia se hacían eco de dicha concepción (Pereira Salas, 1941; Claro y Urrutia, 1973), centrando sus investigaciones en los espacios catedralicios como principales centros de actividad musical, desde los que se irradiaba hacia los lugares de menor "importancia"2. Como afirma Vera (2004, p. 109), esta concepción permitió estudiar la forma en que se difundió la actividad musical durante la colonia, al mismo tiempo que produjo la marginación de todo lo que no fuera conceptualizado como centro (conventos, monasterios, regiones, la música privada de las clases subalternas, etc.). Para la tradición historiográfica y musicológica que se fundamentó en esta metáfora, las cosas realmente interesantes pasaban en el centro, y esta visión se reflejó en la forma que adoptó su discurso histórico.

Sin embargo, consideramos que el problema no radica en el concepto de centro y periferia, sino en el literalismo por el cual es concebido. En otras palabras, solo puede ser perjudicial para una visión posmoderna de la musicología si se desconoce que es un término metafórico. Y como tal, creemos que su carga metafórica puede ser provechosa, reconociendo su valía como herramienta conceptual y epistemológica. Desde un punto de vista metafórico, podemos concebir el centro no solo geográficamente, sino también cultural y socialmente. Desde una perspectiva histórica, la sociedad colonial puede ser entendida no solo piramidalmente, sino también a través de esta metáfora, ubicando en el centro a las clases hegemónicas y en la periferia a las subalternas. Si eso es así para el entramado social, también lo es para las prácticas culturales, entre ellas la música. Concibiendo unas prácticas socialmente aceptadas, que incluyen estilos, ocasionalidades, repertorios, músicos e instrumentos, como centro, concebimos inmediatamente lo que queda en la periferia, o incluso en ese "afuera" mencionado más arriba. Así existen prácticas, costumbres, espacios y estilos considerados como propios del centro, otros de la periferia, y otros más allá de lo aceptable.

Consideramos que la visión del centro y la periferia no tiene necesariamente que significar el estudio de uno de estos componentes en forma aislada, sino que puede ser de gran 
utilidad la investigación de las relaciones existentes entre sí. En este sentido, el trabajo de Miguel Ángel Marín (2002) ha sido un hito no solo para la musicología española, puesto que permite abstraer una visión metodológica aplicable en diferentes contextos. Además, desde el punto de vista de la historia de las ideas, la reciente obra del profesor Eduardo Devés (2012) permite valorar la utilización de esta metáfora para entender la dinámica de la circulación de ideas en diversos tipos de sociedades coloniales.

\section{LA PRESENCIA DE LO SECULAR Y LA REACCIÓN DE LA INSTITUCIONALIDAD RELIGIOSA DURANTE EL PERIODO COLONIAL}

La presencia de la música en las manifestaciones religiosas de las culturas es un hecho constante temporal y geográficamente. Será una característica del ámbito colonial español ofrecernos numerosos ejemplos testimoniales de cómo este fenómeno tiene puntos en común entre la religiosidad peninsular y la indígena: la presencia permanente de elementos seculares, pero que en el mundo indígena representan una fuerte carga identitaria, mientras que en el mundo europeo tienen un carácter funcional, bien establecido dentro del culto.

La música transmitida a través de los siglos ha representado para la Iglesia una riqueza de incalculable valor y se ha distinguido entre todas las demás artes porque, combinada con la palabra, constituye una parte integrante y necesaria de la liturgia solemne. Por eso esta vinculación del canto y la música es uno de los pilares fundamentales para que la manifestación musical tenga el sentido dentro del contexto de la celebración. De esta manera, el arte musical en la Iglesia no puede ser entendido solamente desde el punto de vista estético, sino desde el que tiene que prestar dentro de la liturgia. De otra manera la música perdería su relación y sentido con el contexto al que es llamada, ya que la liturgia significa, ante todo, la actualización del misterio de salvación con un contenido abstracto y sobrenatural (Ramos, 2000, p. 131). Además, no debemos olvidar que la Iglesia concibe la música como un arte doblemente funcional: sacramental y ministerial. Se usa como medio de expresión de una actitud de alabanza (actitud interior de la asamblea, cauce de las formas de adoración, fe, alabanza, acción de gracias, meditación, súplica y comunión) y con una función ministerial, es decir, al servicio del misterio de Cristo y de la Iglesia en su realización ritual, festiva y sacramental (Cabrera, 2009, p. 9).

La presencia de elementos seculares en los templos chilenos es propia del proceso de aculturación por parte de la población indígena y se produce desde la llegada del peninsular a la zona central y la llamada frontera del reino. Vera documenta la temprana presencia de indios yanaconas en la plaza de cantores en la catedral de Santiago, haciendo hincapié en la particularidad de esta situación, ya que la presencia de indígenas a cargo del canto sagrado escapa a la tendencia colonial de que los indios solo ocupasen puestos de instrumentistas (2008, p. 13). El antecedente es interesante porque nos da cuenta de la presencia de estratos indígenas en la principal capilla musical del reino, lo que permitirá que desde la fundación de las ciudades con sus correspondientes cabildos eclesiásticos incorporen músicos ajenos a la formación tradicional recibida por los religiosos, abriéndose así a la posibilidad de que permeen elementos autóctonos e identitarios en una celebración de carácter sagrado y estrictamente normada por las autoridades civiles y eclesiásticas.

La presencia de dichos elementos puede comprobarse por las constantes señales de disconformidad que las autoridades eclesiásticas manifestaron frente a todo lo que se alejaba del espíritu pío que debía llevar consigo el repertorio tradicional. Ya en el siglo XVII los estilos 
musicales dejaron de ser exclusivamente el canto llano y la polifonía clásica, para dar paso a una música que incorporó elementos originales de la ópera, el madrigal y la música instrumental. Un buen ejemplo de esto es el desarrollo y transformación del villancico, el cual ya a principios del siglo XVIII incorporó elementos de la cantata de cámara y de la música teatral con influencia italiana (Bombi, 2007, p. 150). De esta manera, los estilos de música permitida nos sitúan frente a una de las más trascendentes señales de la Iglesia postridentina, al incorporarse algunos aspectos que ya se daban con fuerza en las colonias y que era imposible dejar de considerar.

Los intentos de querer erradicar todo aspecto considerado profano se pierden en la historia medieval española, en un proceso que se extendió como el canon europeo cristiano a través de las formas del barroco y los métodos de la contrarreforma católica según el Concilio de Trento (Salinas, 2000, p. 50). Según Salinas, el Concilio concibió el arte y la música como un medio de adoctrinamiento en el canon monocultural del occidente cristiano, adoctrinamiento que, tomando en cuenta la situación sufragánea de Chile del virreinato del Perú, debió seguirse con los mismos pasos y recurrir a los mismos procedimientos que se utilizaron allí (Guarda, 2009, p. 132).

Así, la institución en Chile experimentó un desarrollo importante con la fundación del obispado de Santiago en 1561 y de La Imperial en 1563, este último equidistante de las ciudades de Concepción y Osorno, eje de los territorios del sur del Reino. Tal situación se debió a un intento de posibilitar el buen gobierno de las diócesis, puesto que ya la Capitanía tenía una posición periférica con respecto del Virreinato de Lima. El obispado de Santiago abarcaba desde el río Copiapó, por el norte, hasta el río Maule, por el sur, y Cuyo, al otro lado de la Cordillera de Los Andes, incluyendo la ciudades de Mendoza y San Juan; y el de La Imperial abarcaba desde el Maule hasta Magallanes, incluyendo los territorios de Chiloé. De tal forma, en su origen, la Iglesia chilena quedó dividida en dos obispados, cuyos centros diocesanos estaban separados por más de 700 kilómetros. A principios del siglo XVII se consolidó la ciudad de Santiago como capital del Reino, especialmente al establecerse allí la Real Audiencia, lo que significó paulatinamente el paso del obispado y las ciudades del sur, devastadas por la guerra, desde una posición, que podemos conceptualizar como centro, a una periférica. Con este panorama geopolítico, la Iglesia chilena logró establecer la ortodoxia colonial tras el tercer Concilio Limense (1582-1583)³, que se constituirá en el elemento central que intentará plasmar la uniformidad de la exposición de la doctrina en todo el territorio, como el gran constituyente de la cultura e identidad iberoamericana.

Como hemos señalado, en Chile las constituciones sinoidales intentaron frenar enérgicamente las manifestaciones festivas de los pueblos, como bien lo expone Salinas (2000, p. 51). En Santiago las ordenanzas sinodales presentan extensas normativas frente a estos aspectos, y reiteran explícitamente los preceptos del Tercer Concilio Limense, ya que si bien los primeros tres sínodos que se dieron en Chile se encuentran perdidos, el sínodo del Obispo de Santiago, Fr. Bernardo Carrasco, de 1688, reitera que se guarden y observen los decretos constitucionales del Concilio Provincial de Lima de 1583 (Carrasco, 1691, pp. 8-9).

Una de las principales ordenanzas tiene relación con la música interpretada en los espacios públicos, específicamente en las puertas de los monasterios de monjas, prohibiendo se den músicas y bailes que pudiesen alterar las costumbres de las jóvenes religiosas, quienes, recordemos, en forma general pertenecían a las más conspicuas familias del Reino, dado el alto costo económico que representaba el pago de la dote por su admisión.

Ordenamos a todas las Preladas de los Monasterios no permitan se dé música en las puertas

a ninguna persona de fuera, ni baylen en ellas, ni las niñas de educación, porque es muy gráde 
el desorden de concursos, que se junta alsi de los de fuera, como de las de adentro, faltando

al recogimiento interior del Monasterio, y a la modestia religiosa (...) y los dichos agasajos de musicas se podran hazer en los locutorios sin bayles, y por ninguna suerte se hagan en la Iglesia (...). (Carrasco, 1691, p. 31)

En la cita se puede observar la dinámica del fenómeno del centro y la periferia, ya que se establece claramente una frontera entre lo que está "adentro" y lo que debe permanecer "afuera" del espacio religioso conventual. Dentro de lo que debe permanecer "afuera", vemos que Carrasco incluye a personas y manifestaciones culturales, como la música y el baile, las cuales quedan así claramente perfiladas como periféricas para el ambiente conventual, dejando dentro de la primera categoría personas ("niñas de educación" y novicias) y actitudes, como el recogimiento interior y la modestia religiosa. Además, se refuerza la frontera entre estos dos espacios al condenar la mezcla entre los de "adentro" y los de "afuera". Por otra parte, además de la suspensión de la prelada que contraviniera el mandato, la ordenanza buscaba que la música, claramente de un carácter alegre y festivo, se hiciese en los locutorios, delimitando específicamente un espacio para lo previamente considerado periférico, y otro para el centro (la Iglesia). Seguía así el modelo impuesto por Lima de austeridad, solemnidad y absoluto orden y respeto por la liturgia, simbolizado por el canto gregoriano y la polifonía palestriniana.

Este proceder no solo se restringió a los espacios conventuales, sino que lo encontramos también para los templos y los oficios divinos. Constatamos nuevamente la delimitación estricta de los espacios y las manifestaciones que les eran propias, junto a una dinámica de restricción y aceptación. Por ejemplo, el citado sínodo intentó prohibir cantos profanos en medio de los oficios, específicamente la interposición de "(...) Psalmos de Tercia, Romances y tonos a la guitarra (...)" (Carrasco, 1691, p. 31), por alejarse dicha práctica de las disposiciones establecidas. Sin embargo, encontramos más adelante en el mismo documento que la restricción fue solo parcial, por lo siguiente:

Mandamos, que solo antes de la Tercia se diga un tono, y otro acabada, antes de comenzar la Missa y los demás en las partes de la Missa, que acostumbran, por ser mas del agrado de Dios le alaben con cantos sagrados, que con letras, que tal vez desdizen del lugar, y del culto.

(Carrasco, 1691, p. 31)

Como podemos constatar, los intentos de la Iglesia en las colonias americanas, si bien son categóricos en reglamentar cuidadosamente el espacio que la música de los estratos populares pudiera tener en templos y monasterios, ya manifiesta a finales del XVII cierta permeabilidad hacia manifestaciones que se dan con fuerza y que legítimamente representan la religiosidad popular colonial. Según Vera (2009, p. 91), esta actitud de relativa tolerancia se explica como una estrategia desarrollada por Roma a partir del Concilio de Trento para atraer a los estratos populares y expandir de manera más efectiva su doctrina.

El sínodo de Concepción, convocado por el Obispo Azúa e Irigoyen el 11 de octubre de 1744 con un aparatoso ceremonial de estilo, viene en gran medida a reiterar la costumbre virreinal de erradicar las músicas populares como tonos y villancicos y todo tipo de abusos dados por la no promulgación de ley eclesiástica alguna en el obispado desde hace 171 años. Sin embargo se observa la gran influencia del sínodo de Santiago del Obispo Carrasco, al que alude explícitamente (Oviedo, 1964, p. 35). 
En la constitución XIX, De las músicas en los templos, encontramos lo siguiente:

Debiendo solo captar nuestra atención en las Iglesias aquella suave psalmodia, que elevando el corazón a Dios, fervoriza nuestra devoción, se han introducido los recitados, y tonos á la modulación nueva, y profana, que desdice mucho de los Templos, como lo dá á entender el cap. De Vitandis in celebratione Missa, feff. 22 del Trident. Pues aunque no sean impuros los versos, (que siempre debe suponerse) á lo menos puedan excitar las voces al auditorio á las mismas tocatas, que en sus festines, y cenas profanas estilan, lo que no vaca de culpa en el sentir de los A.A. por lo que se previene la abstención de esas tocatas, y músicas profanas, aunque sean las letras á lo Divino, y por los Villancicos burlescos de los Mytines de Navidad, se moderen de aquella summa jocosidad, que hace el bullicio, una farsa el Choro, examinándose siempre por el que precediere en él. (Azúa, s.a., p. 65)

De la cita se desprende que lo que se rechaza es especialmente el elemento secular por incitar a un espíritu alejado del canonizado por el centro, el que insiste en el recogimiento propio de la liturgia, dedicada a un dios todopoderoso y absoluto. No debemos olvidar que el sacrificio de la misa significa la presencia real, según el dogma católico, de Dios como víctima propiciatoria, por lo cual es congruente la admonición al recogimiento. A nuestro juicio, es imprescindible tomar en cuenta las constricciones estéticas del barroco, puesto que se considera al arte musical como un agente capaz de mover las pasiones y, por lo tanto, con poder para influir en la conducta de las personas.

Otro ejemplo notable de los intentos de la Iglesia por controlar las manifestaciones festivas de los sujetos se da en el ámbito de las cofradías coloniales:

Es muy grande el desorden, que hay, al pedir las limosnas en las mesas particulares, y generales, que acostumbra cada Cofradia en las puestas de las Iglesias, y aun dentro de ellas, profanandolas con las vocerías, bayles, y bevidas, q se reparten a todos los que van a dar limosnas prosiguiendo en esta profanidad hasta dos, y tres horas de la noche abiertas las Iglesias. (Carrasco, 1691, p. 34)

Nuevamente podemos constatar el establecimiento de una delimitación entre lo de adentro, propio del espacio sagrado, y un afuera, en el que se pueden realizar ciertas actividades. En la cita se critica la actividad de las cofradías, las que con el fin de recaudar fondos transgredían estos límites de dos formas. Por una parte, causando "desorden" en las puertas y en el interior de los templos, $y$, por otra, profanando el espacio consagrado al dar pie a actividades impropias como los bailes, ingestión de bebidas y "vocerías" hasta altas horas de la noche. Aquellas actividades no son rechazadas en sí mismas sino por las circunstancias en que se llevaban a cabo. Esto indica que lo que se quiere mantener alejado es el espíritu festivo y profano de un espacio concebido como un lugar sagrado dentro de la doctrina católica, lo que implica el respeto irrestricto a la figura de Cristo crucificado, ya que es en dicho lugar donde se realiza diariamente el sacrificio de la divinidad encarnada para la expiación de los pecados. La represión de lo festivo y profano no se puede entender solo como un rechazo a unas prácticas culturales propias de las clases subalternas, sino también hay que tomar en cuenta las constricciones propias del catolicismo barroco español ${ }^{5}$. Esto se ejemplifica también en un testimonio del cura de la Iglesia Matriz de San Luis (Cuyo), D. Juan Venegas de Toledo, fechado el 23 de febrero de 1679, quien manifiesta su molestia por el comportamiento del Corregidor D. Juan de La Banda, quien "se puso a la puerta de dicha Iglesia a bailar al són de una harpa" 
(Espejo, 1954, p. 278). Nuevamente, encontramos que lo que se critica es la acción festiva que se lleva a cabo en un lugar sagrado y no la acción en sí misma.

Cierto tipo de expresiones festivas populares estuvieron ligadas especialmente a grupos subalternos, como los agrupados en las cofradías. La actividad de dichas organizaciones fue sujeto de una activa vigilancia por parte de las autoridades eclesiásticas. En el sínodo de 1688, el obispo Carrasco dispuso que:

(...) las dos Cofradias, que están fundadas en el Colegio de la Compañía de lesvs de esta Ciudad, la una de los Indios naturales con la advocación del Niño IESVS, y la otra de morenos con la de nuestra Señora de Belen, se agreguen, la de los Indios a la de nuestra Señora de Copacabana, fundada en el Couento del señor S. Francisco, y la de N. Señora de Belen a la de los morenos, fundada en el Conuento de Predicadores del señor Santo Domingo de dicha Ciudad, y desde luego queden agregadas, y vnidas, ó se seshagan. (Carrasco, 1691, p. 35)

Podemos ver claramente que la intención de la autoridad es desvincular a estas cofradías, que agrupaban a clases marginales, de su institución de origen, disolviéndolas en otras. El obispo no da la razón de esta disposición, sin embargo el historiador de la Orden jesuita, Francisco Enrich, nos revela su verdadera causa de la siguiente forma:

(...) la prudente condescendencia con que les permitían [los jesuitas] mezclar con algunas prácticas de ella cantares, danzas, festines y otros sencillos desahogos, no podrán menos de quedar desagradablemente sorprendidos cuando sepan cómo en este año de 1686 quisieron los PP. quitar de sus cofradías todo lo que estuviese poco conforme con la gravedad del culto católico, prohibiéndoles á los naturales y morenos sus cánticos risueños, razonamientos chistosos, festivas danzas y opíparas comilonas. (Enrich, 1891, p. 8)

Es decir, es el choque con la "gravedad del culto católico" lo que convierte a estas manifestaciones festivas, expresadas en espacios religiosos, en parte de lo periférico que debe ser contenido. Esta represión de lo festivo, más allá de constreñir la música profana per se, se dirige a la constricción de un tipo de sociabilidad que emana espontáneamente de los sujetos sociales comunes. Además de las cofradías, las fiestas religiosas en los espacios públicos representaron otras ocasiones en las que se dieron manifestaciones profanas. Como lo demuestra el padre Ovalle, desde los inicios de la ocupación hispana las capas sociales periféricas participaron en las fiestas con el uso de sus propias expresiones musicales.

La religiosidad popular encontró un lugar privilegiado en las zonas rurales, siendo las cofradías uno de los vehículos más importantes en la expresión de dicho fenómeno. La constitución XIV del sínodo de Concepción, se refiere específicamente al control de las manifestaciones festivas en los campos de la manera siguiente:

Siendo la Erección de las Cofraternidades dirigidas al Religioso Culto de Dios Nuestro Señor, de su Santisima Madre, y de los Santos, para que con la protección de su Patrocinio nos auxiliemos en esta vida mortal, para conseguir la eterna; está introducida principalmente en las de Campaña una profanación tan irreverente en las Fiestas, que se acostumbran en ella, que mas parecen bacanales, ó regosijos públicos de los Theatros, que demostración piadosa de la devoción, originándose de esta subversión, no solo el que se disipen las limosnas en assumptos tan extraños del Culto, sino muchos pecados públicos, y escandalosos en el consorcio de hombres, y mugeres, dispersos en la Campaña, muchos días con la provocación consiguiente 
á semejantes concursos; por lo que seriamente manda esta Synodo á todos los Curas, á cuyo distrito pertenecieren las Cofradias, que pena de Excomunion mayor, no permitan Comedias, Toros, ni otras diversiones profanas en las fiestas de dichas Cofradias, en las quales solo atiendan al Culto del Señor, ó Santo Patron Tutelar, en una Missa cantada, con la cera, y asseo correspondiente, excitando á los Cofrades, á que frecuenten en ella los Santos Sacramentos, que es la más acceptable celebración del Divino Culto; y só la misma pena de Excomunion se manda á los Mayordomos, no disipen las cortas entradas de Cofradias, en commensaciones, ebriedades, y otros desperdicios, que solo fomentan los vicios, atrasando la devoción, y que de ninguna suerte se les admitirá en descargo de su cuenta semejantes gastos, excepto solo los que impendieren en dar de comer á los Músicos, y sirvientes de la festividad, con una mediana moderación. (Azúa, s.a., pp. 114-115)

Vera (2009, pp. 315-316) expone un testimonio del obispo Alday de 1757 que da cuenta de que estas formas de encarar las fiestas también se daban en las doctrinas de campaña del arzobispado de Santiago. De hecho, Alday condena de una manera similar algunas costumbres profanas como el concurso de ambos sexos, las ramadas, los juegos y el consumo de bebidas. Además, es interesante señalar que se responsabiliza a los mayordomos de las cofradías del fomento de los excesos descritos ${ }^{6}$. Siete años más tarde, las disposiciones sinodales del obispo Alday reiteran la supresión de este tipo de prácticas en las devociones en los campos, lo que nos permite pensar que el grado de influencia que realmente pudieron tener las constituciones en la constricción de dichas prácticas fue muy leve, ya que de haber sido exitosas no serían reiteradas de manera tan enérgica por parte de la Iglesia en un lapso de tiempo tan extenso temporalmente (1744 a 1763) y geográficamente.

Otro testimonio que reafirma lo anteriormente expuesto lo encontramos en octubre de 1712. En las crónicas del viajero francés Frezier encontramos una descripción de las fiestas del Rosario en Valparaíso. Es interesante revisar su testimonio:

Dificil seria relatar los asuntos de ella, pues eran variados imui seguidos; propiamente hablando no eran mas que intermedios de farsas mezclados con danzas ibailes mui bien ejecutados iaun hermosos a la manera del pais. La música consistía en una arpa i algunas guitarras ovihuelas. Pero los qne hacia ridículo i poco edificante el recitado era la mezcla impertinente de alabanzas a Nuestra Senora del Rosario ide chabacanas bufonadas i obscenidades poco veladas. (Frezier, 1902, p. 73)

Debemos tomar en cuenta que las fiestas en el espacio público del barroco colonial implicaban un punto de encuentro entre las diversas etnias y clases sociales, haciendo posible el tránsito de una práctica popular propia de espacios privados al espacio público y de celebración religiosa.

En la ciudad de Talca, la situación no parece distar a los hechos descritos por Frezier en Valparaíso, ya que las primeras noticias acerca de actividades que incluyeran música en celebraciones religiosas en la Villa las encontramos a solo unos años de su fundación como Villa de San Agustín de Talca en 1742. Si bien estas están relacionadas con festividades puramente religiosas, no están vinculadas directamente a las órdenes religiosas presentes en la Villa, principalmente Agustinos y Mercedarios, sino que son organizadas y practicadas por miembros comunes del vecindario, entregándonos una interesante noticia de participación de estratos populares en celebraciones religiosas fuera de Santiago. Estas, motivadas por diversas circunstancias, son una verdadera explosión de la religiosidad colectiva popular. Estas celebraciones consistían en 
ingenuos simulacros de elementos alegóricos y pastoriles a la usanza de España, equivalentes a las procesiones que precedieron a la formación del teatro clásico (Ramos, 2010, p. 35)

Podemos constatar la existencia de dichas celebraciones ya en 1759, a solo 17 años de la fundación de la Villa, donde son los propios gremios los llamados a organizar y ejecutar las festividades de celebración por la colocación de la Iglesia Mayor de la Villa.

El cabildo en sesión ordinaria deja constancia en acta del siguiente modo:

Ya acordaron esthos señores que los gremios hiciesen mojigangas y algunos bailes a la colocacion de la iglesia mayor para lo que ya fueron llamados (...). (AHN, 1759, f. 2-3)

Una situación similar se da en el norte del reino, ya que según el Acta del cabildo de La Serena del 11 de abril de 1752, se ordena para la festividad de Corpus Christie:

(...) que los gremios concurran a la plaza con sus festivas invenciones, que ayuden a celebrar estas fiestas i procesiones i se encarga al gremio de plateros i caldereros la música i se le nombran capitanes al alferez Claudio Nuñez y José de Tapia. (Concha, 1871, p. 98)

En definitiva, la presencia de la música en las actividades religiosas con participación directa de miembros de las clases sociales diversas en el periodo colonial nos da muestras de la existencia de expresiones netamente populares, que un importante grado de sincretismo (desde la raigambre hispana del motivo de las celebraciones, hasta quienes son los verdaderos actores de dichas expresiones) será influyente en la conformación de una religiosidad que veremos manifestarse con cada vez mayor vigor durante el siglo precedente.

Ahora bien, tal fenómeno también está presente en la vida privada colonial, específicamente en las celebraciones de las fiestas en las casas de los particulares. El obispo Carrasco prohíbe el hacer altares en las casas porque:

(...) los dias, y noches del Nacimiento de N. Señor IESU Christo, S. Juan Baptista, y de la Santa

Cruz, en que hay muchas ofensas de nuestro Señor, por los concursos de hombres, y muge-

res, bailes, y musicas profanas, é indecentes. (Carrasco, 1691, p. 44)

La anterior disposición corresponde a un documento emanado del arzobispado de Santiago en las postrimerías del siglo XVII, sin embargo, constatamos que la costumbre de hacer celebraciones religiosas en las casas de los particulares prosigue décadas más tarde, en la zona sur del reino, comprobando la unidad de criterios y disposiciones frente a lo considerado periférico. Lo anterior puede ser demostrado con la siguiente cita, extraída del sínodo diocesano de Concepción de 1744:

Los días mas sagrados de la Navidad del Señor, de la Purisima Concepcion, de la Santa Cruz, y del Gloriosos Precursor San Juan Baptista, con pretexto de pía devoción, se suelen acostumbrar en las casas particulares Altares, que profanados con el concurso popular de hombres, y mujeres, músicas, y festines, se toma por motivo el assupto de religiosa piedad para la mayor Deprabacion, por lo que esta Sinodo manda seriamente, só pena de Excomunion mayor, no se acostumbren dichos Altares en las casas los días referidos, ni otros algunos. (Azúa, s.a., p. 158)

Azúa, además de prohibir los festines, bailes y músicas profanas en los días de fiesta por constituir ocasiones pecaminosas, estipula que "se quite el abuso de los responsos cantados en la casa de los difuntos, después de habérsele enterrado y volver al duelo a ellas" (Azúa, 
s.a., p. 60), entregándonos un primer antecedente del rechazo de las autoridades eclesiásticas a los cantos populares propios de las ceremonias fúnebres en el ámbito privado.

Desde la perspectiva de los conceptos tratados al inicio de nuestro estudio hasta el momento hemos presentado antecedentes que comprueban la persistencia de la actitud restrictiva de la Iglesia católica frente a las prácticas profanas desarrolladas en espacios y ocasionalidades religiosas que se daban en la cultura colonial. Sin embargo, como también hemos señalado, la reiteración de estas restricciones a lo largo de casi un siglo abarcando las dos diócesis del reino demuestran la persistencia de dichas prácticas. Estas restricciones delimitan un centro representado por una actitud piadosa, espacios consagrados para el culto y la devoción, y ocasionalidades específicas de acuerdo con el calendario litúrgico, y una periferia representada por prácticas culturales profanas, consideradas por lo tanto indebidas, que se daban en la cultura religiosa colonial.

\section{EL NUEVO ORDEN REPUBLICANO: EXPRESIONES Y REPRESIONES DE LAS MANIFESTACIONES POPULARES}

La Iglesia en Chile durante el siglo XIX, al igual que en otras regiones del antiguo imperio español, se encontró en una difícil situación al finalizar las guerras de independencia. Generaba verdaderos problemas el hecho de la dependencia de la diócesis de Santiago y Concepción del Arzobispado Metropolitano de Lima, mientras que los obispados locales debían franquear grandes obstáculos para llevar su ministerio en espacios geográficos enormes que comprendían latitudes tan extremas como de Concepción al Cabo de Hornos. No fueron pocos los antagonismos surgidos dentro de la Iglesia en la guerra de independencia, y a las continuas irregularidades en monasterios y conventos se sumaba el hecho de que en los años de independencia muy pocos sacerdotes se habían ordenado. Muchos edificios de las iglesias y conventos se encontraban en un estado deplorable (Krebs, 2002, p. 134). Sin embargo, en medio de las difíciles condiciones existentes la tradición religiosa había conservado toda su fuerza, y los valores y las formas de la religión católica seguían orientando la vida pública y privada. Se mantuvieron la unión Estado-Iglesia y el regalismo, considerándose que la república debía seguir siendo un Estado católico. Luego del fracaso de la misión de O'Higgins de establecer relaciones directas con la Santa Sede, la iglesia quedó entregada a su propia suerte y su desarrollo fue determinado por las decisiones de su propio clero y por las resoluciones del gobierno. Las medidas más importantes obedecieron al espíritu y a los objetivos del catolicismo ilustrado y constituyeron una continuación de las reformas iniciadas por los ministros de Carlos III (Krebs, 2002, p. 135). Tras largos y complejos procesos vinculados al nombramiento de los principales prelados en el país, la Santa Sede, en conformidad con la política iniciada por León XII, y seguida por Gregorio XVI, de reconocer a las nuevas repúblicas y establecer relaciones con sus gobiernos normalizando la situación de la iglesia, decidió nombrar obispos diocesanos para las dos diócesis chilenas. Dicha normalización coincidió con la consolidación de la república bajo el ministerio de Portales y el presidente Prieto. Los conservadores que continuaron el gobierno durante decenios siguientes mantuvieron la unidad de Estado e Iglesia y la apoyaron por auténticos motivos religiosos o por intereses de conveniencia política, generando un discurso común en cuanto a (des)conocer la presencia cada vez mayor de una clase social popular, decidida a expresarse en la vida pública y espiritual. Estas élites intelectuales y políticas, que arrancan con las exigencias de la Europa ilustrada de finales del siglo XVIII, implantan una 
actitud general frente a la idea de expresarse libremente, con modificaciones estéticas que buscaban acreditar la seriedad del país, y sobre todo de la incipiente república en el mundo, gravedad ya anunciada en el sínodo diosesano de Santiago de 1763 (en gran parte heredero del de Carrasco) condenando las formas musicales cómicas en los templos de la diócesis.

Contrariamente, la cotidianeidad de las clases populares chilenas, con una actitud diametralmente distinta a la de las élites aristocráticas, circuló en medio de una sociabilidad peculiarmente festiva, viviendo fuera de los mitos urbanos y ciudadanos de la élite que hacían esfuerzos continuos por buscar y dar a conocer las muchas características que las diferenciaban de los "rotos":

El pueblo chileno, todavía rural en sus espacios públicos y privados, y aún más en su espíritu y sentimientos colectivos, volcó su sociabilidad festiva y callejera -como podría definirse el ethos republicano- a través de tres ámbitos específicos de la existencia humana. La comida, la música y el humorismo. (Salinas, 2005, p. 86)

Uno de los aspectos relevantes del proyecto ilustrado de la modernidad tiene relación con que la actividad musical en espacios públicos a partir de las primeras décadas del siglo XIX, se concibe como un elemento socializador del bien simbólico de la música y de la literatura, los cuales se entrecruzan en géneros como la ópera y el canto acompañado. Por esto, los discursos emanados desde las elites permanentemente vincularán el poder simbólico de la democracia con el cultivo de las virtudes morales que acarrea la ilustración y la modernidad, siendo enérgicos en que todo pueblo que al menos pretenda acercarse al ideal del ser "culto" y "civilizado" debe ver las luces de la ilustración.

Esto explica la represión, por parte de las autoridades civiles y religiosas, de tradiciones populares de raigambre colonial. Por ejemplo, en 1839 Manuel Vicuña Larraín, obispo de la diócesis de Santiago, da cuenta de abusos en los oratorios domésticos en la ciudad de Talca y ordena a los párrocos inspeccionarlos, dejando sujeto a licencia la continuidad de dicho espacio (Vicuña, 1839, p. 53). Es interesante recordar las prohibiciones del sínodo de Concepción de 1744, mencionadas anteriormente, acerca de los altares en las casas particulares. Dichas costumbres de origen colonial no se circunscribieron solo a la élite sino que también perduraron en los espacios populares. Entre ellas, una práctica que fue objeto de prohibición, aunque esta vez por las autoridades civiles, fue el velorio privado de un infante. Por ejemplo, en 1857, la municipalidad de Talca prohibió, bajo multa de 4 pesos, “(...) las funciones que bajo el nombre de celebración del Angelito suele tener la gente del pueblo cuando muere algún párvulo (...)" (Opazo, 1942, p. 336).

La intención de restringir lo popular no se circunscribe solo a la población laica, sino que se extiende a los párrocos a fin de salvaguardar "el debido recogimiento", lo que demuestra que el más mínimo contacto con lo profano era considerado pernicioso y alejado de las virtudes morales esperadas para quien ejerciera la actividad ministerial como parte de la Iglesia. Podemos observar esto en el documento dirigido por el obispo Vicuña en 1834 a los eclesiásticos de la doctrina de San Fernando:

Mandamos a todos los clérigos residentes de esta doctrina i a los que en lo sucesivo residieren que empenados en vivir justa i piadosamente no se distraigan en ocupaciones impropias de su sagrado ministerio, que guarden el debido recogimiento i se abstengan de concurrir a juntas i diversiones profanas, en que a mas de la distracccion del espíritu sirven de escandalo 
a los seglares que muchas veces pretenden autorizar ciertos desordenes con su ejemplo.

(Vicuña, 1834, p. 21)

Desde la colonia, las celebraciones de Navidad fueron una ocasionalidad propicia para la mezcla de los mundos profanos y religiosos. Para 1838, Cabrera (2011, p. 78) da cuenta de la persistencia de músicas propias de los ámbitos profanos, como por ejemplo el salón o el teatro, en las liturgias de las festividades de Navidad en el obispado de Santiago, y, junto a ello, la intención de controlar por parte de la Iglesia. Siete años más tarde, el obispo Vicuña reitera una prohibición similar:

A fin de evitar estos males, hemos dispuesto que la dicha celebración del oficio nocturno i misa de medianoche en la festividad del nacimiento de nuestro señor Jesucristo, no se solemnice con otras prácticas que aquellas que el rito de la Santa Iglesia tiene establecidas; según el tenor de las rúbricas del misal i ceremonial romanos, sin que sea permitido añadir cantares con entonaciones profanas, pífanos i otros instrumentos que imitan cantos de aves o gritos de cuadrúpedos, o cualquiera de las cosas que se han acostumbrado otras ocasiones i que rigurosamente no son prevenidas por las mencionadas rúbricas. (Valdivieso, 1845, p. 223) ${ }^{7}$

En el mismo canon de lo anterior, en la zona más periférica del país, la Isla de Chiloé, el recién nombrado obispo de la diócesis de Ancud Justo Donoso declara en la pastoral publicada en 1845 el abuso con que se celebran las funciones religiosas en la isla, manifestando que las prácticas religiosas ya se han depurado de tantos abusos y supersticiones con que la gente manifestaba su ferviente religiosidad en las principales fiestas:

El culto relijioso depurado de ciertas prácticas superticiosas que lo delustraban, se ha presentado mas puro y majestuoso: hanse abolido otras que si bien no podían calificarse de superticiosas, eran de jérmen fecundo de abusos y desordenes deplorables: tales eran, por ejemplo, la flajelacion publica que bajo la ca del disfraz, con el terror y la confianza que inspiraba. Llegó a convertirse en un medio seguro y arto general, de raptos, salteos y otros desordenes: las procesiones nocturnas, en las que las tinieblas, la numerosa concurrencia de ambos sexos apiñada y mezclada indiferentemente, ofrecía una coyontura favorable que sabía aprovechar la inmoralidad para el hurto y la rapiña, y a la vez para la realización de proyectos amatorios fraguados de antemano: las solemnidades llamadas de Aguinaldos y de noche buena, en las que se profanaba escandalosamente la casa del señor, conviertiendola en diversiones de teatro de taberna, en que campeaban las risotadas y entonaban soeces canciones que no pocas veces tenían por objeto zaherir a corporaciones o personas respetables en los indecentes bailes de enmascarados y otras farsas ridículas, en que con el pretesto de piedad y devoción , y de estimular el regosijo público para celebrar la presencia de J.C. en las funciones de Corpus se desahogaban pasiones innobles, recitando romances y haciendo descripciones siempre satíricas e injuriosas, que provocaban inmorales represalias (...). ("Pastoral del Obispo de Ancud", 1845, p. 1, c. 3 y p. 2 , c. 1)

Un fenómeno interesante de resaltar es que a lo largo del siglo XIX la Iglesia concibió paulatinamente como prácticas periféricas algunas costumbres propias de la élite, siendo este un fenómeno que se origina por la creciente influencia de la ópera italiana y el repertorio de numerosas canciones y tonadas de moda en la música sacra chilena. Si bien es cierto que en el periodo colonial la Iglesia intentó restringir las manifestaciones propias de los grupos subalternos, en la era republicana sumará un firme rechazo a la presencia del estilo operístico 
en la liturgia. Pereira Salas da cuenta del gran malestar que el romanticismo lírico produjo en la Iglesia dado que, debido a los progresos de la música profana, la litúrgica había frenado su desarrollo (1941, p. 46) por la introducción de trozos de ópera y piano en importantes celebraciones (Cabrera, 2009, p. 77).

Es importante recalcar que la presencia de músicos extranjeros sirvió de vehículo entre la actividad propia de los espacios profanos y religiosos. En el caso de Santiago, Izquierdo (2013) resalta la figura de Henry Lanza, quien siendo maestro de capilla de la catedral metropolitana desarrolló paralelamente una actividad como cantante en el principal teatro de la ciudad.

En Talca encontramos la figura del conocido director y compositor italiano Rafael PantaneIli, que es un buen ejemplo de cómo músicos extranjeros desarrollaron una actividad musical paralela en los ámbitos religioso y profano. Dicho compositor, director y empresario teatral fundó en 1869 una sociedad musical compuesta por la elite de la ciudad "a fin de que pueda organizarse una orquesta en toda regla" ("Club musical," 1869) dirigida a desarrollar un repertorio principalmente operístico. Por otro lado, constatamos la presencia del músico en el ámbito religioso como compositor y director en importantes celebraciones:

\footnotetext{
El jueves santo a las diez, en la misa parroquial, han cantado el Gloria (cursiva) los alumnos del conservatorio de música. Es admirable lo que han podido hacer en el poco tiempo de estudio que tienen, debido todo a la asiduidad del profesor don R. Pantanelli. Las niñas, pertenecientes a la escuela fiscal n. 2 dirigida por doña Rita Letelier, han tenido la parte más larga i difícil del canto; a los niños, alumnos en su mayor parte de las escuelas de los Seres. Baeza i Aguilera, les ha caído la casuslidad (sic) de estar casi todos en la época de cambio de voz, cosa que no ha permitido apurarles ni darles canto de obra para no hacerlos perder su voz. Lo que contribuyo mucho a dar lucimiento al canto fue la cooperación que presentaron jenerosamente los profesores tanto italianos com chilenos para acompañar el himno: Merced a ello, se pudo tener una pequeña orquesta compuesta de dos violines, dos flautas, dos clarinetes i un corneta a pistón, que acompañados del piano, tocado por el señor Pantanelli, formaban una harmonía muy grata. Sabemos que el señor Pantanelli piensa completar la misa, agregando un Credo i Kiries (cursivas) correspondientes al Gloria que hemos oído, i proporcionado a los conocimientos de sus alumnos: aplaudimos su idea, pues otra vez ya no oiremos aquel credo a secas tan desagradable i que descompuso tanto la función; en estos casos más vale e silencio. ("La Esperanza", 19 de abril 1862, p. 4.)
}

Gracias a este testimonio podemos constatar la presencia de dos fenómenos de suma importancia: por un lado, la heterogeneidad social de quienes interpretan, al estar presente niños y niñas de escuelas fiscales junto a músicos italianos y chilenos que con seguridad formaban parte de la sociedad Pantanelli; y, por otra parte, la instrumentación descrita da cuenta de un repertorio que, si bien es sacro, está escrito en un estilo absolutamente alejado del ideal impuesto por la Iglesia. Finalmente, es interesante la crítica a la forma tradicional de solemnizar el culto. Cuando el cronista habla de "aquel credo a secas tan desagradable i que descompuso tanto la función", nos indica la dicotomía entre el ideal impuesto por la modernidad y los esfuerzos de la Iglesia por mantener la solemnidad que requiere la celebración del culto. Podemos ejemplificar esto en la pugna entre una música religiosa fuertemente influenciada por la ópera italiana y el canto gregoriano.

Respecto a los movimientos de reformas de la música sagrada dentro de la Iglesia, existen evidencias desde el siglo XVII cuando hubo intentos de reglamentar sus usos a través de 
publicaciones tales como Coeremoniales Episcoporum, ordenada por Clemente VIII en 1600, texto declarado obligatorio por Inocencio X, reeditado por Benedicto XIV y reformado por León XIII en 1886 (Cabrera, 2009, p. 77). Sin embargo, el estímulo definitivo a estas reformas vendría desde el sector laico a través de la sociedad ciciliana de Bamberg, movimiento que, naciendo en Alemania en 1868, se propone defender el canto gregoriano y la polifonía a capella como ideales de la Iglesia católica, sin excluir la música moderna, pero siempre que esta estuviera alejada de cualquier elemento operístico. Con la colaboración del compositor Michel Haller, sus miembros publicaron una gran cantidad de música caracterizada por su diatonismo (Randel, 1997, p. 236), textura preferentemente acórdica y relativa simpleza desde el punto de vista compositivo (Vera, 2007, p. 11).

En Chile los intentos de la Iglesia católica por frenar la secularización de la música sagrada no cesarán, y si bien es cierto que se habían manifestado de una manera más bien discreta desde la colonia, no van a ser más decididos hasta las reformas introducidas por el arzobispo Rafael Valentín Valdivieso. En 1847, tras haber suprimido la orquesta de la catedral metropolitana de Santiago por la compra de un gran órgano, el obispo manifestaba su malestar frente a la indisciplina presente en la capilla metropolitana y su intención de poner algo de orden en cuanto a la interpretación de la música sagrada se refiere. La adquisición de este gran instrumento no solo hacía desaparecer la orquesta que permitió por siglos interpretar las composiciones del maestro de capilla de turno, sino que además alejaba decididamente la posibilidad de introducir repertorios sacros con una clara influencia popular, que en este caso se ve representada en tonadas y canciones en boga, tanto de carácter popular festivo o de la ópera o zarzuela de moda. La música acompañada con órgano era mucho más cercana al ideal de música pía que debiera interpretarse en los templos. Por lo anterior, toma relevancia el hecho de que también mercedarios y agustinos adquirieran magníficos órganos, lo que demuestra que la reforma de Valdivieso en la capilla musical metropolitana tuvo una repercusión más amplia ${ }^{9}$.

Tres décadas más tarde, el arzobispo tendrá una actitud más radical al publicar su Edicto sobre música i canto en las iglesias, dirigiéndose a los rectores de iglesias con el objetivo de "promover los cantos sagrados i piadosos i a combatir con teson los abusos que destruyen sus saludables efectos i hasta llegan a ofender la santidad misma del culto que debemos a Dios" (Vera, 2007, p. 11).

Además aboga por el uso generalizado del órgano y no de otros instrumentos, ya que no puede soportarse el abuso de llevar a los templos para los oficios divinos músicas militares y sobre todo suprimir el uso del piano por su naturaleza profana.

Es interesante su mención a la participación de las damas de la época en la música litúrgica, manifestando los inconvenientes que ello conlleva. Lo dice de la siguiente forma:

Omitimos ahora recordar los incontentes que ofrece la mezcla de hombres i mujeres en nuestro coros i la exhibición en ellos de mujeres ataviadas para lucir la maestría i añadir nuevos aplausos a los obtenidos ya en los salones. (Larraín y otros, 1887, p. 1210)

Valdivieso insiste además en extirpar definitivamente el estilo operístico y todo tipo de música teatral de las iglesias, aspecto que, como veremos, iba a ser común a todos los manifiestos similares de épocas posteriores.

Una de las principales censuras a la música sagrada registrada en la época, la única dirigida en especial a todas las diócesis del país, es la "Pastoral Colectiva sobre Música y Canto en las Iglesias de las Diócesis de Chile," publicada en 1887, y que pone énfasis en las restricciones 
a la música de origen popular, declarando que "es el canto sagrado uno de los principales medios con que se tributa culto a la Majestad Divina" (Larraín y otros, 1887, p. 751).

Dado que es la perfección y decoro del culto divino el principal objeto de atención de los servidores de Dios (Larraín y otros, 1887, p. 751), el documento aboga a establecer el canto gregoriano como uno de los principales medios con el que se tribute la majestad divina, manifestando la necesidad de que la iglesia reglamente la recta ejecución de la música sagrada y de los que la interpretan en los templos, tanto en los oficios litúrgicos como en las demás funciones que tiene por objeto tributar culto a Dios, a la Virgen María o a algún santo. Al establecer el canto llano unísono como el de preferencia de la iglesia, se redactan manifiestas prohibiciones referentes a la interpretación de otros estilos, como podemos constatar en el siguiente párrafo:

Se prohibe expresamente en la iglesia toda música vocal compuesta sobre motivos o reminiscencias teatrales o profanas, i aquella que sea compuesta en forma demasiado lijera o muelle, como las cavatinas o los recitados demasiado vivos a la manera teatral, etcétera, etcétera...

Se permiten los solos, los duos i los trios, con tal que sigan el carácter de la melodía sagrada i

estén ligados al conjunto de la composición. (Larraín y otros, 1887, p. 753)

Respecto al uso de instrumentos, ya podemos constatar la importancia que se daba al órgano dentro de la música sagrada. En el artículo tres del mencionado documento, manifiesta claramente esta posición, al establecer que la música de órgano dentro de los templos debe responder al carácter ligado, armónico y grave de este instrumento (Larraín y otros, 1887, p. 752), y que todas sus intervenciones solísticas deban siempre corresponder a la seriedad de la liturgia.

En relación con la fuerte introducción de músicas propias de los salones dentro de los repertorios sacros tradicionales, el documento es enfático al prohibir severamente la ejecución de la más pequeña parte de una reminiscencia de música de obras teatrales o cualquier trozo de baile propio de los salones de cualquiera especie, como polkas, valses, mazurcas, minuetos, schottichs, varsovianas, cuadrillas, galopas, contradanzas y polonesas, y trozos profanos como himnos nacionales, cantos populares, amorosos o bufones, romanzas, etc.

El documento no es el primero ni el único de su tipo, pero al ampliar estas restricciones a las iglesias de todas las diócesis del país nos confirma la idea de que la introducción de aspectos propios de la ópera en los repertorios sacros no era privativa de la capital, sino que también estaba en las iglesias de regiones de manera recurrente. Es interesante que al prohibirse el canto a la mujeres en las iglesias se permita hacerlo "solo en las iglesias pobres i en los lugares que no hai cantores" (Larraín y otros, 1887, p. 752), lo que restringe la común costumbre de escuchar a conspicuas damas lucir las habilidades desarrolladas en los salones. Para impedir los abusos de la música en las iglesias, el documento establece la creación de una comisión encargada de observar las ordenanzas publicadas y censurar las piezas musicales presentes en los archivos de las iglesias; se podían ejecutar solo las composiciones que hayan obtenido el visto bueno de la comisión, llamada Comisión de Santa Cecilia, conformada oficialmente en 1886 y presidida por el presbítero Vicente Carrasco (Ramos, 2011, p. 149). Los verdaderos alcances de este fenómeno, se verán reflejados en la reforma que la iglesia chilena intentará llevar a cabo, cuyos efectos fueron más bien moderados o nulos. 


\section{CONCLUSIONES}

A lo largo de nuestro estudio hemos comprobado que existió por parte de la Iglesia una intención de controlar las manifestaciones musicales profanas en diversos espacios religiosos, como las cofradías, las fiestas de campaña, parroquias, en las casas de los particulares, conventos, etc.; al mismo tiempo, hemos comprobado que dichas manifestaciones persistieron a pesar de los numerosos intentos de la institución por frenarlas. Desde el concepto de centro y periferia planteado al inicio del estudio, podemos entender que la represión de estas manifestaciones no solo materializa un fenómeno de colonialidad que impulsa la hegemonía del centro excluyendo a lo considerado periférico, sino que también refleja una intención de normar en función de mantener la solemnidad del culto dada la función sagrada que el dogma católico le atribuía al rito, absolutamente en concordancia con el espíritu de recogimiento que implica la cosmovisión cristiana del mundo. Finalmente, hemos demostrado que en el siglo XIX la Iglesia amplía la concepción de lo periférico a manifestaciones musicales propias de la burguesía, las cuales surgieron como resultado del proceso modernizador de la sociedad.

\section{NOTAS}

1 Lo anterior obedece a la visión propia del barroco, según la cual lo profano se vincula a lo festivo, considerando el poder de la música para mover a los afectos.

2 En adelante cuando hablemos de la "musicología tradicional" nos referiremos a dichos estudios.

3 Del que perdurarán sus efectos por más de tres siglos hasta la celebración del Concilio Plenario Latinoamericano de 1900 y en muchos aspectos hasta el Concilio Vaticano II (1963).

4 El documento original ha sido rescatado por los autores desde las ruinas del Convento Franciscano de Chillán, y es parte de una investigación llevada a cabo actualmente, vinculada al mencionado convento. Según Oviedo Cavada (1964, p. 283), el documento se titula Primera Sínodo Diocesana celebróla el Iltmo. Señor Doctor D. Pedro Felipe de Azúa, e Iturgoyen, del Consejo de su Majestad, Obispo de esta Santa Iglesia de la Concepción de Chile, después electo Arzobispo de la Metropolitana de Santa Fe del Nuevo reino de Granada, en la Santa Iglesia Catedral de dicha Ciudad de la Concepción, pero el documento original, el cual citamos, carece de las primeras páginas que entregarían esa información. Oviedo Cavada nos informa que el documento que él consultó corresponde a un original custodiado en La Serena y que actualmente se encontraría perdido.

5 Es interesante señalar que la institución de la cofradía como espacio de sociabilidad desde su origen estuvo delimitado por la finalidad de dicha asociación, que dice tener relación con el socorro mutuo, en un sentido primordialmente religiosos y espiritual (Andaur, 2009, pp. 25-29).

6 El corregidor de Rancagua expresa en 1759, precisamente en respuesta al testimonio del Obispo, lo siguiente: "Para lo que sirven [las ramadas], es generalmente para que vayan de esta ciudad muchas vendedoras con vinos, aguardientes y mixtelas [sic], fuera de especies comestibles, y a fin de expenderlas se componen músicas y bailes que atraigan concurso" (Vera, 2009, p. 316).

7 Nótese que el cronista considera el acto litúrgico como una función, denotando la fuerte presencia de lo teatral en la cultura burguesa.

8 La importación de órganos de excelente factura desde Europa se vio reflejada en la instalación de numerosos instrumentos por órdenes religiosas en la capital y las regiones, tomando relevancia la instalación de los primeros órganos construidos por el genial organero francés Arístides Cavaillé Coll y otros de las afamadas firmas Walcker, Merklin, Morettini o Veggessi e Bossi. En cuanto al gran órgano Morettini instalado en la Iglesia de San Agustin, ver Carrasco, 2000. 


\section{REFERENCIAS}

Andaur, Gabriela. "Relaciones interétnicas en Santiago colonial: La cofradía de Nuestra Señora de la Candelaria del Convento de San Agustín (1610-1700)." Seminario para optar al grado de licenciada en Historia, Universidad de Chile. 2009.

Archivo Histórico Nacional (AHN). Actas municipales 1759-1815. Volumen 1, f. 1-3. Municipalidad de Talca.

Azúa e Irigoyen, Felipe. s.t. "De las músicas en los templos". Synodo diocesano de Concepción. Biblioteca colonial convento Franciscano de Chillán, 1745 s.a.

Bombi, Andrea. "'The third villancico was a motet': the villancico and related genres." En Devotional Music in the Iberian World, 1450-1800. The villancico and Related Genres, eds. Knighton Tess y Álvaro Torrente. Aldershot: Ashgate, 2007. 149-187.

“Club musical". El Artesano, Talca, Biblioteca Nacional, sección periódicos (24 de abril de 1869).

“Concilio Vaticano II, Sacrosantum Concilium, capítulo VI, articulo 112. Roma 4 de diciembre de 1963." Humanitas.cl, revista de antropología y cultura cristiana.

Cabrera Silva, Valeska. "La reforma de la música sacra en la iglesia católica chilena". Tesis de maestría, Pontificia Universidad Católica de Chile. Chile: Facultad de Arte, 2009.

Cabrera Silva, Valeska. “La reforma de la música sacra en la iglesia católica chilena. Contexto histórico-social y práctica musical. (1885-1940)." Neuma. Revista de música y docencia musical, Talca, vol. 4, núm. 1 (2011): 70-117.

Carrasco de Saavedra, Bernardo. Synodo Diocesano de Santiago 1688. Lima: Imprenta de loseph de Contreras y Alvarado, 1691.

Carrasco Notario, Guillermo. El órgano Morettini de la iglesia de San Agustín de Santiago. Santiago de Chile: Ediciones Agustinianas, 2000.

Claro Valdés, Samuel y Urrutia, Blondel Jorge. Historia de la música en Chile. Santiago: Instituto de investigaciones musicales, Universidad de Chile, Editorial Orbe, 1973.

Concha, Manuel, Crónica de La Serena, desde su fundación hasta nuestros días. 1549-1870. La Serena: Imprenta de la Reforma, 1871

Devés-Valdés, Eduardo. Pensamiento periférico. Asia - África - América Latina - Eurasia y algo más. Una tesis interpretativa global. Santiago de Chile: IDEA-USACH, 2012.

Enrich P., Francisco. Historia de la Compañía de Jesús en Chile, tomo II. Barcelona: Giménez y Roca, 1891.

Espejo, Juan Luis. La Provincia de Cuyo del Reino de Chile, Tomo I. Santiago de Chile: Fondo Histórico y Bibliográfico José Toribio Medina, 1954.

Frezier,Francois. Relación del viaje por el mar del sur a las costas de Chile i el Perú durante los años de 1712, 1713 y 1714, trad. Nicolás Peña M. Santiago de Chile: Imprenta Mejía, 1902.

Guarda Geywitz, Gabriel. "Metodología misional en Chile. Siglos XVI-XVIII". En Historia de la Iglesia en Chile. En los caminos de la conquista espiritual, dir. Marcial Sánchez Gaete. I t. Santiago: Editorial Universitaria, 2009. 121-158.

Izquierdo, José y Lía Rojic. “Henry Lanza: música, ópera, modernidad y religiosidad en la construcción cultural de la república chilena temprana (1840-1860)." Neuma. Revista de música y docencia musical, Talca: vol. 6, núm. 1 (2013): 10-29.

Izquierdo, José. El Gran Órgano de la Catedral de Santiago de Chile." Música y modernidad en una ciudad republicana (1840-1860). Santiago de Chile: Ediciones Universidad Católica de Chile, 2013.

Krebs W., Ricardo. La iglesia en América Latina en el siglo XIX. Santiago de Chile: Ediciones Universidad Católica de Chile, 2002. 
Larraín, Joaquín y otros. "Pastoral colectiva sobre la música i canto en las Iglesias de las Diócesis de Chile." En Boletín Eclesiástico: o sea colección de edictos, estatutos i decretos de los prelados del Arzobispado de Santiago de Chile. Vol. IX. Santiago de Chile, Imprenta del Correo, 1887. 751-758.

Marín, Miguel Ángel. Music on the Margin. Urban musical life in eighteenth-century Jaca (Spain). Kassel: Edition Reichenberger, 2002.

Meyer, Leonard. El Estilo en la Música. Madrid: Ediciones Pirámide, 2000.

Opazo Maturana, Gustavo. Historia de Talca. Santiago de Chile: Imprenta Universitaria, 1942.

Oviedo Cavada, Carlos. Sínodos y Concilios Chilenos. 1584 (?) 1961. Santiago: Instituto de Historia, Universidad Católica de Chile, 1964.

"Pastoral del Obispo de Ancud". El Alfa, Talca, núm. 25 (12 de abril de 1845).

Pereira Salas, Los orígenes del arte musical en Chile. Santiago de Chile: Ediciones de la Universidad de Chile, 1941.

Randel, Don Michael. Diccionario Harvard de Música, trad. esp. Luis Gogo. Madrid: Editorial Alianza, 1997.

Ramos, José Domingo. Juan Sebastián Bach, Las Cantatas y la Pastoral del Canto. Salamanca: Ed. Pontificia Universidad de Salamanca, 2000.

Ramos, José Miguel. “El corpus musical de la iglesia del hospicio de Talca: una aproximación a la actividad musical en la ciudad antes del Concilio Vaticano II" (1857-1916)". Neuma. Revista de música y docencia musical, año 3 (2010): 34-57.

Ramos, José Miguel. “El corpus musical de la iglesia del hospicio de Talca: un aproximación a la actividad musical en la ciudad antes del Concilio Vaticano II (1857-1916)". Tesis de maestría, Universidad de los Lagos. Osorno, Facultad de Ciencias Humanas, 2011.

Salinas, Maximiliano. "¡Toquen flautas y tambores!: Una Historia Social de la Música desde las Culturas Populares en Chile. Siglos XVI-XX". Revista musical Chilena, vol. 54, núm. 193 (2000): 47-82.

Salinas, Maximiliano. "Comida, música y humor. La desbordada vida popular". En Historia de la vida privada en Chile. Tomo II. El Chile moderno de 1840 a 1925, dirs. Rafael Sagredo y Critían Gasmuri. Santiago de Chile: Aguilar Chilena de Ediciones, 2005. 85-117.

"Semana Santa". La Esperanza, Talca, (19 de abril de 1862).

Valdivieso, Rafael. "Se prohíben celebraciones indebidas en la Pascua de Navidad".

Boletín Eclesiástico: o sea colección de edictos, estatutos i decretos de los prelados del Arzobispado de Santiago de Chile, Santiago: Imprenta del Correo. I (1845): 223.

Vera, Alejandro. "Las agrupaciones instrumentales en las ciudades e instituciones periféricas de la colonia: el caso de Santiago de Chile." En Música Colonial Iberoamericana: interpretaciones en torno a la práctica de ejecución y ejecución de la práctica, Actas del V Encuentro simposio internacional de musicología "Misiones de Chiquitos."Víctor Rondón (Ed.). Santa Cruz de la Sierra: Fondo Editorial Asociación Pro Arte y Cultura, 2004.

Vera, Alejandro. “En torno a un nuevo corpus musical en la iglesia de San Ignacio: música, religión y sociedad en Santiago (1856-1925)," Revista Musical Chilena, Año LXI, Nº 208, 2007

Vera, Alejandro. “Entre marginalidad y decoro: Una aproximación al papel de la música en la constitución del nuevo reino de Chile (1541-1700)". Neuma. Revista de música y docencia musical, Talca, vol. 1 (2008): 10-19.

Vera, Alejandro. "La música en los espacios religiosos". En Historia de la Iglesia en Chile. En los caminos de la conquista espiritual, dir. Marcial Sánchez Gaete. I t. Santiago: Editorial Universitaria, 2009. 289-322.

Vicuña, Manuel. "Se ordena la visita de los oratorios de la ciudad de Talca, i se detalla lo que es prohibido hacer en ellos". Boletín Eclesiástico: o sea colección de edictos, estatutos i 
decretos de los prelados del Arzobispado de Santiago de Chile, Santiago, Volumen I (18301832) $N^{\circ}$ 22. (1839) p. 53.

Vicuña, Manuel. "Sobre lo que deben observar los eclesiásticos residentes en la doctrina de San Fernando". Boletín Eclesiástico: o sea colección de edictos, estatutos i decretos de los prelados del Arzobispado de Santiago de Chile, Santiago, Volumen I (1830-1832) N 4 (1834) p. 21.

\section{Cómo citar este artículo:}

Ramos Fuentes, José Miguel; Martínez García, Gonzalo.

“Transgresión y persistencia: la represión de las manifestaciones musicales profanas en los espacios religiosos de la periferia chilena. Siglos XVI-XIX". Cuadernos de música, artes visuales y artes escénicas, 9 (2), 147-167, 2014. http:// dx.doi.org/10.11144/Javeriana.mavae9-2.tprm 
